\title{
The Association Between Ready-to-Eat Cereal Consumption, Nutrient Intakes of the Canadian Population 12 Years and Older and Body Weight Measures: Results From a Nationally Representative Canadian Population
}

\author{
Ann M. Albertson ${ }^{1}$, Sandra G. Affenito ${ }^{2}$, Julie M. Culp ${ }^{1}$, Pierrette Buklis ${ }^{3} \&$ Nandan A. Joshi ${ }^{4}$ \\ ${ }^{1}$ Bell Institute of Health and Nutrition, General Mills Inc., Minneapolis,USA \\ ${ }^{2}$ School of Health and Natural Sciences, Univeristy of Saint Joseph, West Hartford,USA \\ ${ }^{3}$ General Mills Inc.,Canada \\ ${ }^{4}$ General Mills India Pvt. Ltd., Mumbai,India \\ Correspondence: Ann M. Albertson, Principle Nutrition Research Scientist, General Mills: Bell Institute of \\ Health and Nutrition, James Ford Bell Technical Centre, 9000 Plymouth Avenue North, Minneapolis, MN 55427, \\ Tel: 763-764-4133. E-mail: ann.albertson@genmills.com
}

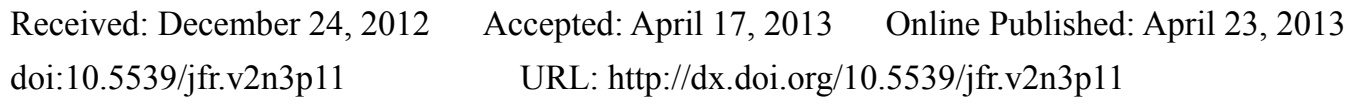

This research was funded by General Mills Inc., Minneapolis, MN

\begin{abstract}
Background: To examine the relationship between ready-to-eat (RTE) cereal consumption habits and body mass index (BMI) of a nationally representative sample of Canadians. Methods: Population-based survey of Canadians aged 12 years and older. Participants provided 7-day self-reported food diary records during the data collection period of October 2003 through September 2004. Height and weight of the respondents was also reported. Main outcome measures included frequency of RTE cereal consumption, Body Mass Index (BMI), and nutrient intakes. The sample population of 2926 aged 12 years and older was divided into three groups by frequency of RTE cereal consumption over the 7-day period: 0-1 serving, 2-3 servings and 4+ servings. Results: The RTE cereal intake ranged from 0 to greater than 8 servings over the 7 days. Males who consumed $4+$ servings of RTE Cereal had significantly lower mean BMI measures than the ones who consumed $0-1$ serving $(\mathrm{P}<0.006)$. Significantly lower proportion of Canadians who consumed 4+ serving of RTE cereal were classified as overweight or obese than those who consumed $0-1$ servings in seven days $(\mathrm{p}=0.011)$. Higher cereal intake group also had favourable nutrient intake profiles than the lower cereal intake group and were more likely to meet micronutrient intake recommendations. Conclusion: Self-reported RTE cereal consumption is related to lower BMI and improved nutrient intake in Canadians aged 12 years and older.
\end{abstract}

Keywords: ready-to-eat (RTE) cereal, nutrient intake, body mass index (BMI)

\section{Introduction}

In recent decades, overweight and obesity are increasing health-related concerns among the adolescent and adult populations in Canada (Langlois, Garriguet, \& Findlay, 2009; Vanasse, Demers, Hemiari, \& Courteau, 2006). Between 1985 and 1998, there was an almost threefold increase in obesity among Canadian adults, from 5.6\% to $14.7 \%$, respectively (Katzmarzyk, 2002). In addition, the 2004 Canadian Community Health Survey documented a $23.1 \%$ prevalence of obesity among individuals greater than eighteen years of age. These data demonstrate that obesity increased with age, but did not differ between men and women. However, it is noteworthy that the rates of obesity vary across Canadian health regions (Vanasse et al., 2006). These differences in obesity rates may be related to a number of factors including socioeconomic status, household income, education, or amendable lifestyle behaviours such as dietary intake, eating habits, and physical activity (Vanasse et al., 2006; Langlois et al., 2009; Garriguet, 2009; McLaren, Godley, \& MacNairn, 2009). The etiology for obesity is complex and is influenced by modifiable lifestyle habits, such as eating patterns and physical activity, environmental and psychosocial factors and non-modifiable genetic determinants (Bray \& Champagne, 2005). Similar to the results 
of studies conducted in the United States (U.S.) (Kant \& Graubard, 2006; Bowman \& Vinyard, 2004; Howarth, Huang, Roberts, Lin, \& McCrory, 2007) empirical research demonstrates that eating habits are changing among Canadians. Canadians are consuming more meals away from home (Woodruff \& Hanning, 2009), with increased consumption of high energy, nutrient poor foods (Slater et al., 2009) and reduced intake of fresh fruit, vegetables and fibre (Langlois et al., 2009). These dietary changes likely negatively impact the body weight of Canadians. For example, empirical data have shown an association between persons who consume diets high in fibre and healthy body weights (Burgess-Champoux, Larson, Neumark-Sztainer, Hannan, \& Story, 2010; Williams, Grafenauer, \& O'Shea, 2008; Steffen et al., 2003) and, when adjusted for covariates, increased total energy and reduced fibre intake were significantly associated with obesity among men (Langlois et al., 2009).

In addition to consuming more meals away from home, there is evidence which points to the unfavourable association between breakfast omission and regulation of body weight. Research has shown that persons who skip breakfast are at increased risk for overweight (Williams, O'Neil, Keast, Cho, \& Nicklas, 2009; Keski-Rahkonen, Kaprio, Rissanen, Virkkunen, \& Rose, 2003; Cho, Dietrich, Brown, Clark, \& Block, 2003; Ma et al., 2003). Breakfast consumption may be an indicator for associated healthful lifestyle behaviours including adequate physical activity patterns and enhanced nutrient intake and a high quality dietary intake (Song et al., 2006; Barton et al., 2005; Cho et al., 2003), thus facilitating body weight regulation (Song et al., 2005; Barton et al., 2005; Keski-Rahkonen et al., 2003). Across age groups, a commonly preferred breakfast selection is ready-to-eat (RTE) cereal because of its accessibility, taste, convenience, cost, and availability (Nicklas, McQuarrie, Fastnaught, \&O’Neil, 2002; Williams et al., 2009).

There are over 160 varieties of ready-to-eat (RTE) cereal available across Canada. Many cereals are made from whole grains and provide fibre. A typical serving of Canadian RTE cereals is $3 / 4 \mathrm{c}(175 \mathrm{~mL})$ to $1 \mathrm{c}(250 \mathrm{~mL})$. This is true of the most commonly consumed varieties, although nutrition information among these leading choices is presented in two reference amounts-either $30 \mathrm{~g}$ or $55 \mathrm{~g}$. Nearly all RTE cereals in Canada are fortified according to the voluntary standard permitted by Health Canada, where it is possible to add, singly or in combination a specifically limited amount of only the following vitamins and minerals: thiamine, niacin, vitamin $\mathrm{B}_{6}$, folic acid, pantothenic acid, magnesium, iron and zinc. Breakfast cereals are also typically low in fat and contain $<10 \mathrm{~g}$ of sugar per serving.

Ready-to-eat (RTE) cereal has the potential tonot only increase micronutrient, fibre, and whole grain intake, but to aid body weight control (Albertson et al., 2009; Albertson et al., 2008; Albertson Anderson, Crockett, \&Goebel, 2003; Barton et al., 2005; Gibson, 2003; Berkey, Rockett, Gillman, Field, \& Colditz, 2003). Indeed, studies conducted in the U.S. have documented an inverse association between the frequency of RTE cereal consumption and body weight (Albertson et al., 2003; Albertson et al., 2008; Albertson et al., 2009; Barton et al., 2005; Cho et al., 2003). To date, these data are not available for the Canadian population. Therefore, this research investigated the impact of RTE cereal consumption patterns on BMI and nutrient intake in Canadians ages 12+ using 7-day food intake methodology.

\section{Methods}

\subsection{Dietary Intake Assessment}

To determine the contribution of food consumption patterns on nutrient intake, a unique, proprietary nutrient assessment methodology was developed at the General Mills Bell Institute of Health and Nutrition (Albertson et al., 2003). This methodology combines National Eating Trends (NET) food diary data from the NPD Group (Canada, Toronto) with portion size estimates derived from six years of National Health and Nutrition Examination Survey (NHANES) collection, 1999-2004 (CDC) and nutrient data from the University of Minnesota's Nutrition Data System for Research (NDS-R) version 2008 (Nutrition Coordinating Centre, Minneapolis, MN). The resulting integrated database is processed and analysed using SAS ${ }^{\circ}$ Version 9.2 (SAS Institute, Cary, NC).

\subsubsection{Food Consumption Data/Participants}

The current study uses the comprehensive food consumption data set made available from the NPD Group, a marketing information company, with their National Eating Trends ${ }^{\circledR}$ (NET) service. NET has been continuously tracking the eating habits of Americans since 1980 and Canadian population since 1998. The present research presents results on food intake from approximately 1700 households representing approximately 4,000 individuals. The sample is weighted to reflect the Canadian census based on region, household size, income, homemaker age/employment and ethnicity. The diary and reporting procedures are the same as in the U.S. 
This study utilized NET data collected from October 2003 through September 2004, as documented by the Canadian Census Bureau database, which is balanced according to demographics and geographics. The variables are reported at the household level and include the ages of panel participants as well as household data such as income level, size, and age of head of household. Employment status and race are also reported. NET data are provided for fifty-two sub samples whereby nearly forty households record all food and beverages consumed weekly by all household members. Seasonal variations in food intake are considered as well, as the reporting is distributed evenly throughout the year. A daily "eating diary" for one week is maintained by each household. The person most responsible for meal preparation is instructed to record the name and brand of each food and beverage consumed by all members of the household, including all additives, ingredients and cooking aids.

The diary consists of separate sections for each meal and snack situation, and collects food names, flavour descriptors, brand names, package types, product forms, appliances used in preparation, and any special nutritional attributes, among other details. The same information is collected on ingredient and additive items used to create dishes or meals in the home. At the end of each day, the recorder is instructed to mail the daily diary back to The NPD Group. After all seven daily diaries are received from a household; they are coded and made ready for data processing. The sample of 1700 households (approximately 4,300 subjects, including 3531 individuals ages 12 and older) used for this study was weighted to match Canadian demographics (Table 1). Out of the 3531 individuals ages 12 and older, 2926 had complete BMI information and did not meet criteria for underreporting and, thus, were used for analysis. These persons were categorized according to their gender and RTE cereal consumption pattern.

Table 1. Canadian Demographics from Statistics Canada, 2005

\begin{tabular}{lll}
\hline Demographic & & $\%$ Census \\
\hline Female Head Age & $18-24$ & $4.1 \%$ \\
& $25-34$ & $16.2 \%$ \\
& $35-49$ & $32.6 \%$ \\
Household Income $^{1}$ & $50-64$ & $26.3 \%$ \\
& $65+$ & $20.9 \%$ \\
& $<20$ & $14.1 \%$ \\
Household Size & $20-34$ & $16.1 \%$ \\
& $35-59$ & $24.1 \%$ \\
& $60+$ & $45.6 \%$ \\
& 1 Member & $26.8 \%$ \\
& 2 Member & $33.6 \%$ \\
Presence of Children & 3 Member & $15.9 \%$ \\
& 4 Member & $14.7 \%$ \\
& $5+$ Member & $8.9 \%$ \\
& Under 12 & $14.3 \%$ \\
& 12 to 18 & $10.7 \%$ \\
& Both & $5.7 \%$ \\
& No Kids & $69.3 \%$ \\
\hline
\end{tabular}

${ }^{1}$ Household income reported in thousands of dollar.

\subsubsection{Portion-Size Data}

Canadian NET panellists record the foods and beverages consumed by household members but not the quantities. This procedure is standard for panel surveys to minimize recorder burden and thus increase reliability. Because national Canadian portion size data were unavailable, age and gender specific mean portion weights derived from NHANES 1999-2004 were assigned to each food recorded in the diary. Serving weights for individual food codes were aggregated and then collapsed for like-foods to strengthen cell sizes, and smoothed to eliminate outliers. Age and gender- specific mean serving weights were thereby determined for over 800 food types; these portions were subsequently assigned to each food recorded and coded in the NET diary. 


\subsubsection{Nutrient Data}

Using the recipe component of the Nutrition Data System for Research (NDS-R) software, the investigators recorded and coded the nutrient values as documented in the NET diary. The NDS-R software analysis is precise and provides a complete nutrient values for 160 nutrients for more than 18,000 foods, including many brand-name products. Each food or recipe was entered into NDS-R per 100 grams of that food, and closely matched to the description provided in the NET diary. Recipes were created to account for foods with special nutritional attributes (i.e. low fat, fat-free, low cholesterol, calcium fortified, low sodium, or reduced sodium). Because NDS-R reports nutrient values for the U.S. food supply, considerable adjustment were made "recipes" to match nutrient values reported in Canadian Nutrient File (CNF) (Health Canada, Canadian Nutrient File, 2007). Particular attention was made to enriched and fortified foods such as ready-to-eat cereals and dairy products.

\subsection{Data Tabulation}

In order to estimate the potential effect of RTE cereal consumption on body weight measures and nutrient intakes, the frequency of RTE cereal consumption in 7 days was recorded for each participant. Intake of cereal was considered as a categorical variable. Because the distribution of cereal is not symmetrical and somewhat truncated, quartiles were not used to categorize the data. Rather, the population was classified into three groups based on cereal consumption patterns during the 7-day data collection period: 0-1, 2-3 servings and 4 servings and more servings. For the purposes of this analysis, a "serving" is a record of cereal consumption and is assigned an age/gender appropriate mean serving amount.

\subsection{Body Mass Index}

Individual, self-reported heights and weights were recorded in the diary for each respondent and used to calculate BMI according to the formula

$$
B M I=\text { weight }\left(\text { kilograms) } / \text { height }(\text { meters })^{2}\right.
$$

Overweight was defined as a BMI $\geq 25$ and obese was defined as a BMI $\geq 30$ (29). Study sample participants who did not record height and/or weight $(\mathrm{n}=605)$ were excluded from the analysis. Final sample size of the study was 2926 adults (1246 men and 1680 women).

Table 2. Distribution of sample population by age, gender and BMI

\begin{tabular}{lc}
\hline Age-group & \% Distribution \\
\hline $12-18$ & 6.1 \\
$19-50$ & 48.6 \\
$51-70$ & 33.4 \\
$71+$ & 11.9 \\
\hline Gender & \% Distribution \\
\hline Male & 42.6 \\
Female & 57.4 \\
\hline Quantile & BMI Distribution \\
\hline $100 \%$ & 54.8 \\
$99 \%$ & 43.9 \\
$95 \%$ & 37.4 \\
$90 \%$ & 33.7 \\
$75 \%$ & 29.3 \\
$50 \%$ & 25.8 \\
$25 \%$ & 22.8 \\
$10 \%$ & 20.6 \\
$5 \%$ & 19.4 \\
$1 \%$ & 17.2 \\
$0 \%$ & 12.7 \\
\hline
\end{tabular}




\subsection{Statistical Analysis}

Means or proportions were computed by age and gender and according to RTE intake category. Analysis of variance was used to determine if BMI, per cent overweight/obese differed by age and RTE consumption categories. Pair wise t-tests were performed where differences were found among the categories. Logistic regression was used to analyse the association between total energy, macronutrient intake, RTE consumption pattern and intake. The contrasts were examined between the possible pairs of cereal consumption categories using the Wald chi-square. An alpha level of 0.05 was used to determine significance for the analysis of variance comparisons except where otherwise noted. All analyses were performed using SAS ${ }^{\circledR}$ version 9.2 (SAS Institute, Cary, NC).

\section{Results}

Over the seven days of dietary collection, intake ranged from zero to greater than eight servings of RTE cereal (Figure 1).

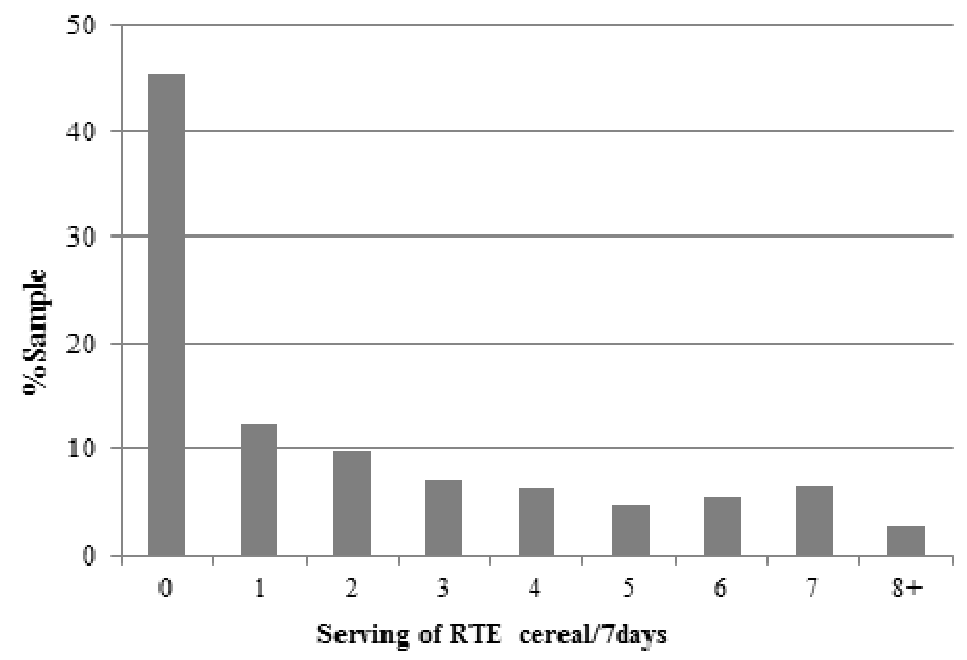

Figure 1: The distribution of ready-to-eat (RTE) cereal consumption among Canadians aged 12 years and older $(\mathrm{n}=2,926)$ over the 7-day collection period

An inverse relationship between BMI and frequency of RTE cereal consumption for the total sample was directionally favorable but did not reach statistical significance $(\mathrm{p}=0.062)$ (Table 3$)$.

Table 3. Mean body mass index (BMI) of Canadians age 12 and older $(n=2,926)$ by gender and cereal consumption tertiles ${ }^{1}$

\begin{tabular}{|c|c|c|c|c|c|c|c|c|c|}
\hline & \multicolumn{2}{|c|}{ 0-1 Servings } & \multicolumn{2}{|c|}{ 2-3 Servings } & \multicolumn{2}{|c|}{ 4+ Servings } & \multicolumn{2}{|c|}{ Total } & \multirow{2}{*}{ p-value } \\
\hline & Mean \pm SEM & $\mathrm{n}$ & Mean \pm SEM & $\mathrm{n}$ & Mean \pm SEM & $\mathrm{n}$ & Mean \pm SEM & $\mathrm{n}$ & \\
\hline Male & $27.4 \pm 0.19^{\mathrm{a}}$ & 744 & $26.7 \pm 0.35^{\mathrm{ab}}$ & 196 & $26.0 \pm 0.25^{b}$ & 306 & $27.0 \pm 0.14$ & 1246 & 0.006 \\
\hline Female & $26.6 \pm 0.20$ & 954 & $26.5 \pm 0.39$ & 298 & $26.3 \pm 0.30$ & 428 & $26.5 \pm 0.16$ & 1680 & 0.835 \\
\hline Total & $27.0 \pm 0.14^{\mathrm{a}}$ & 1698 & $26.5 \pm 0.27^{\mathrm{ab}}$ & 494 & $26.2 \pm 0.21^{\mathrm{b}}$ & 734 & $26.7 \pm 0.11$ & 2926 & 0.062 \\
\hline
\end{tabular}

${ }^{1}$ Means within the same row with different letters are statistically significantly different $(\mathrm{p}<0.05)$.

This relationship was statistically significant when males were considered alone $(p<0.006)$; however, did not hold true for females $(\mathrm{p}=0.835)$. A statistically significant inverse relationship also existed for the proportion of overweight or obese and frequency of cereal consumption (Table 4). The proportion of Canadians aged 12 and older who were overweight or obese were significantly lower for those consuming four or more servings of RTE cereal during a seven day period than those consuming $0-1$ servings in seven days $(\mathrm{p}=0.011)$ (Table 4). This relationship was also directionally favorable by gender, but did not reach statistical significance. 
Table 4. Percentage of Canadians aged $12(n=2,926)$ or older categorized as overweight or obese by gender and the frequency of cereal consumption ${ }^{1}$

\begin{tabular}{|c|c|c|c|c|c|c|c|c|c|}
\hline & \multicolumn{2}{|c|}{ 0-1 Servings } & \multicolumn{2}{|c|}{ 2-3 Servings } & \multicolumn{2}{|c|}{ 4+ Servings } & \multicolumn{2}{|c|}{ Total } & \multirow[b]{2}{*}{ p-value } \\
\hline & $\begin{array}{l}\% \\
\text { Overweight/ } \\
\text { Obese }\end{array}$ & $\mathrm{n}$ & $\begin{array}{l}\% \\
\text { Overweight/ } \\
\text { Obese }\end{array}$ & $\mathrm{n}$ & $\begin{array}{l}\% \\
\text { Overweight } \\
\text { / Obese }\end{array}$ & $\mathrm{n}$ & $\begin{array}{l}\% \\
\text { Overweig } \\
\text { ht/ Obese }\end{array}$ & $\mathrm{n}$ & \\
\hline Male & $67.5^{\mathrm{a}}$ & 744 & $61.2^{\mathrm{ab}}$ & 196 & $59.5^{\mathrm{b}}$ & 306 & 64.5 & 1246 & 0.028 \\
\hline Female & 53.9 & 954 & 50.0 & 298 & 50.2 & 428 & 52.3 & 1680 & 0.314 \\
\hline Total & $59.8^{\mathrm{a}}$ & 1698 & $54.5^{\mathrm{b}}$ & 494 & $54.1^{\mathrm{b}}$ & 734 & 57.5 & 2926 & 0.011 \\
\hline
\end{tabular}

${ }^{1}$ Percentages within the same row with different letters are statistically significantly different $(\mathrm{p}<0.05)$.

Total daily energy intake differed across cereal consumption tertiles (Table 5). There was a positive association between cereal consumption frequency and energy intake $(\mathrm{p}<0.0001)$. Despite this association, there were no differences in total daily fat, saturated fat, trans fat, or cholesterol intake among cereal consumption tertiles (Table 5).Daily intakes of fibre, potassium, vitamin A, vitamin C, vitamin E, thiamin, riboflavin, niacin, vitamin B6, folate, vitamin B12, calcium, vitamin D, magnesium, iron and zinc all increased with increasing consumption of RTE cereal (Table 5), and each of these relationships was statistically significant.

Table 5. Mean Nutrient Daily Intake of Canadians aged 12 years and older $(n=2,926)$ by Cereal Consumption Tertiles $^{1}$

\begin{tabular}{|c|c|c|c|c|c|}
\hline \multirow{3}{*}{ Nutrients } & \multicolumn{4}{|c|}{ Cereal Consumption } & \multirow{3}{*}{ p-value } \\
\hline & 0-1 Servings & 2-3 Servings & 4+ Servings & Total & \\
\hline & $\mathrm{n}=1698$ & $n=494$ & $\mathrm{n}=734$ & $\mathrm{n}=2926$ & \\
\hline Energy (kcal) & $1853.4 \pm 751.6^{\mathrm{a}}$ & $1970.3 \pm 734.9^{b}$ & $2083 \pm 800.8^{\mathrm{c}}$ & $1930.7 \pm 767.5$ & $<0.001$ \\
\hline Total CHO (g) & $222.5 \pm 101.2^{\mathrm{a}}$ & $250.1 \pm 96.8^{b}$ & $274.6 \pm 108.3^{\mathrm{c}}$ & $240.2 \pm 104.6$ & $<0.001$ \\
\hline Total Fat (g) & $74.2 \pm 31.2^{\mathrm{a}}$ & $75.3 \pm 31.2^{\mathrm{a}}$ & $76.2 \pm 33.6^{\mathrm{a}}$ & $74.9 \pm 31.8$ & 0.351 \\
\hline Saturated Fat (g) & $25.3 \pm 11.5^{\mathrm{a}}$ & $25.8 \pm 11.6^{\mathrm{a}}$ & $26.1 \pm 12.7^{\mathrm{a}}$ & $25.6 \pm 11.8$ & 0.293 \\
\hline Trans Fat (g) & $5.8 \pm 2.9^{\mathrm{a}}$ & $5.9 \pm 3.1^{\mathrm{a}}$ & $5.7 \pm 3.3^{\mathrm{a}}$ & $5.8 \pm 3.1$ & 0.650 \\
\hline Cholesterol (mg) & $257.5 \pm 134.5^{\mathrm{a}}$ & $260 \pm 128.8^{\mathrm{a}}$ & $249.1 \pm 123^{\mathrm{a}}$ & $255.8 \pm 130.7$ & 0.254 \\
\hline Total Protein (g) & $71.5 \pm 26.8^{\mathrm{a}}$ & $75.6 \pm 27.5^{b}$ & $80 \pm 28.3^{c}$ & $74.3 \pm 27.5$ & $<0.001$ \\
\hline Total Sugar (g) & $100.2 \pm 64^{\mathrm{a}}$ & $114.3 \pm 60.3^{b}$ & $126.2 \pm 63.6^{\mathrm{c}}$ & $109.1 \pm 64.2$ & $<0.001$ \\
\hline Dietary Fiber (g) & $13.6 \pm 6.1^{\mathrm{a}}$ & $16.3 \pm 6.6^{\mathrm{b}}$ & $20 \pm 9.5^{\mathrm{c}}$ & $15.6 \pm 7.7$ & $<0.001$ \\
\hline Sodium (mg) & $3355.7 \pm 1316.9^{\mathrm{a}}$ & $3551.3 \pm 1341.1^{b}$ & $3548.3 \pm 1340.5^{\mathrm{b}}$ & $3437.1 \pm 1330$ & 0.001 \\
\hline Potassium (mg) & $2407.1 \pm 941^{\mathrm{a}}$ & $2682 \pm 1007.1^{\mathrm{b}}$ & $3015 \pm 1050^{\mathrm{c}}$ & $2606 \pm 1013.4$ & $<0.001$ \\
\hline Vitamin A (mcg rae) & $613.8 \pm 503.6^{\mathrm{a}}$ & $688 \pm 508.2^{\mathrm{b}}$ & $735 \pm 518.2^{\mathrm{b}}$ & $656.7 \pm 510.6$ & $<0.001$ \\
\hline Vitamin C (mg) & $76.6 \pm 62.4^{\mathrm{a}}$ & $88 \pm 63.5^{\mathrm{b}}$ & $103.4 \pm 67^{\mathrm{c}}$ & $85.3 \pm 64.7$ & $<0.001$ \\
\hline Vitamin E (mg $\alpha$-tocopherol) & $5.4 \pm 3^{\mathrm{a}}$ & $5.6 \pm 2.8^{\mathrm{ab}}$ & $5.9 \pm 3.1^{\mathrm{b}}$ & $5.5 \pm 3$ & 0.001 \\
\hline Thiamin (mg) & $1.6 \pm 0.6^{\mathrm{a}}$ & $1.9 \pm 0.7^{\mathrm{b}}$ & $2.4 \pm 1^{\mathrm{c}}$ & $1.8 \pm 0.8$ & $<0.001$ \\
\hline Riboflavin (mg) & $1.9 \pm 0.8^{\mathrm{a}}$ & $2.1 \pm 0.8^{\mathrm{b}}$ & $2.3 \pm 0.9^{c}$ & $2 \pm 0.8$ & $<0.001$ \\
\hline Niacin $(\mathrm{mg})$ & $20.4 \pm 7.9^{\mathrm{a}}$ & $21.4 \pm 8.3^{\mathrm{b}}$ & $22.9 \pm 8.4^{\mathrm{c}}$ & $21.2 \pm 8.2$ & $<0.001$ \\
\hline Vitamin B6 (mg) & $1.4 \pm 0.6^{\mathrm{a}}$ & $1.6 \pm 0.6^{\mathrm{b}}$ & $1.8 \pm 0.7^{\mathrm{c}}$ & $1.6 \pm 0.6$ & $<0.001$ \\
\hline Folate (mcg) & $439 \pm 179.3^{\mathrm{a}}$ & $464.7 \pm 180.5^{\mathrm{b}}$ & $488.1 \pm 184.6^{\mathrm{c}}$ & $455.7 \pm 182$ & $<0.001$ \\
\hline Vitamin B12 (mg) & $4.1 \pm 2.9^{\mathrm{a}}$ & $4.6 \pm 3^{b}$ & $4.9 \pm 3.1^{\mathrm{b}}$ & $4.4 \pm 3$ & $<0.001$ \\
\hline Calcium (mg) & $713 \pm 363.8^{\mathrm{a}}$ & $818.2 \pm 379.2^{\mathrm{b}}$ & $909.2 \pm 401.9^{c}$ & $780 \pm 385.4$ & $<0.001$ \\
\hline Vitamin D (mcg) & $4.2 \pm 2.8^{\mathrm{a}}$ & $5.1 \pm 2.8^{\mathrm{b}}$ & $5.9 \pm 3.2^{\mathrm{c}}$ & $4.8 \pm 3$ & $<0.001$ \\
\hline Magnesium (mg) & $232.4 \pm 94.2^{\mathrm{a}}$ & $266.1 \pm 100.5^{\mathrm{b}}$ & $308.8 \pm 121.1^{\mathrm{c}}$ & $257.2 \pm 107.5$ & $<0.001$ \\
\hline Iron $(\mathrm{mg})$ & $11.6 \pm 4.5^{\mathrm{a}}$ & $14.1 \pm 4.7^{\mathrm{b}}$ & $17.3 \pm 6.9^{\mathrm{c}}$ & $13.5 \pm 5.8$ & $<0.001$ \\
\hline Zinc (mg) & $9.0 \pm 4.8^{\mathrm{a}}$ & $9.7 \pm 3.8^{b}$ & $10.5 \pm 3.9^{\mathrm{c}}$ & $9.5 \pm 4.5$ & $<0.001$ \\
\hline
\end{tabular}

${ }^{1}$ Means within the same row with different letters are statistically significantly different $(\mathrm{p}<0.05)$. 
The percentage of the population consuming less than $100 \%$ of their EARs was also analyzed by cereal consumption tertile. A high proportion of the sample did not meet their EARs for vitamin E (96.2\%), magnesium (69.1\%) and vitamin A (51.5\%) (Table 6). The proportion of Canadians not meeting their EARs for vitamin A, vitamin $\mathrm{C}$, thiamin, riboflavin, niacin, vitamin $\mathrm{B} 6$, vitamin $\mathrm{B} 12$, folate, magnesium, iron and zinc was significantly greater in the lowest tertile of cereal consumption (0-1 servings) when compared to the highest (4+ servings) (Table 6).

Table 6. Percentage of Canadians aged 12 and older $(n=2,926)$ not meeting their estimated average requirement (EAR) by cereal consumption tertiles ${ }^{1}$

\begin{tabular}{|c|c|c|c|c|c|}
\hline \multirow[b]{2}{*}{ Nutrients } & \multicolumn{4}{|c|}{ Cereal Consumption } & \multirow[b]{2}{*}{ p-value } \\
\hline & $\begin{array}{l}0-1 \text { Servings } \\
\mathrm{n}=1698\end{array}$ & $\begin{array}{l}2-3 \\
\text { Servings } \\
n=494\end{array}$ & $\begin{array}{l}4+ \\
\text { Servings } \\
n=734\end{array}$ & $\begin{array}{l}\text { Total } \\
n=2926\end{array}$ & \\
\hline Vitamin A (mcg rae) & $57.54^{\mathrm{a}}$ & $49.39^{\mathrm{b}}$ & $39.10^{\mathrm{c}}$ & 51.54 & $<0.001$ \\
\hline Vitamin C (mg) & $54.53^{\mathrm{a}}$ & $43.52^{\mathrm{b}}$ & $33.51^{\mathrm{c}}$ & 47.40 & $<0.001$ \\
\hline Vitamin E (mg $\alpha$-tocopherol) & $96.70^{\mathrm{a}}$ & $97.57^{\mathrm{a}}$ & $94.28^{\mathrm{b}}$ & 96.24 & 0.004 \\
\hline Thiamin (mg) & $13.07^{\mathrm{a}}$ & $2.63^{\mathrm{b}}$ & $1.36^{\mathrm{b}}$ & 8.37 & $<0.001$ \\
\hline Riboflavin (mg) & $9.42^{\mathrm{a}}$ & $3.85^{\mathrm{b}}$ & $3.00^{\mathrm{b}}$ & 6.87 & $<0.001$ \\
\hline Niacin (mg) & $9.36^{\mathrm{a}}$ & $5.87^{\mathrm{b}}$ & $3.68^{\mathrm{b}}$ & 7.35 & $<0.001$ \\
\hline Vitamin B6 (mg) & $38.99^{\mathrm{a}}$ & $27.33^{\mathrm{b}}$ & $16.08^{\mathrm{c}}$ & 31.27 & $<0.001$ \\
\hline Folate (mcg) & $26.44^{\mathrm{a}}$ & $21.46^{\mathrm{b}}$ & $15.53^{\mathrm{c}}$ & 22.86 & $<0.001$ \\
\hline Vitamin B12 (mg) & $15.31^{\mathrm{a}}$ & $7.49^{\mathrm{b}}$ & $6.54^{\mathrm{b}}$ & 11.79 & $<0.001$ \\
\hline Magnesium (mg) & $78.21^{\mathrm{a}}$ & $63.77^{\mathrm{b}}$ & $51.77^{\mathrm{c}}$ & 69.14 & $<0.001$ \\
\hline Iron (mg) & $13.25^{\mathrm{a}}$ & $2.83^{\mathrm{b}}$ & $0.27^{\mathrm{c}}$ & 8.24 & $<0.001$ \\
\hline Zinc (mg) & $42.05^{\mathrm{a}}$ & $32.79^{\mathrm{b}}$ & $22.62^{\mathrm{c}}$ & 35.61 & $<0.001$ \\
\hline Calcium & $71.32^{\mathrm{a}}$ & $63.16^{\mathrm{b}}$ & $53.95^{\mathrm{c}}$ & 65.58 & $<0.0001$ \\
\hline Vitamin D & $95.58^{\mathrm{a}}$ & $94.53^{\mathrm{a}}$ & $88.15^{\mathrm{b}}$ & 93.54 & $<0.0001$ \\
\hline
\end{tabular}

\section{Discussion}

To date, this research is the first to present the findings of RTE cereal consumption patterns on body weight measures and nutrient intake in Canadians aged twelve years or greater, using validated 7-day food intake methodology. Similar to previous studies conducted among persons in the U.S. (Albertson et al., 2003; Albertson et al., 2009; Barton et al., 2005; Cho et al., 2003; Song et al., 2005), this research demonstrated a positive association between consumption of RTE cereal and body weight measures. However, unlike past studies (Albertson et al., 2003; Albertson et al., 2009; Barton et al., 2005; Cho et al., 2003), the association between RTE cereal consumption and BMI differed by gender and weight status. An inverse assocation between BMI and frequency of RTE cereal consumption was statistically significant for males, as well as for the proportion of overweight or obese persons in the full sample population. Other research has shown that there are gender- and age-related differences in regularity in breakfast consumption, and hence RTE cereal intake. More specifically, evidence demonstrates that females omit breakfast more often than males, and this pattern of intake begins as children transition through adolescenceand is often related to the desire to lose weight (Woodruff \& Hanning, 2009; Rampersaud et al., 2005; Berkey et al., 2003) Further, in efforts to lose weight, those persons who are overweight or obese omit the breakfast meal more often compared with those of normal weight (Alexander et al., 2009; Williams et al., 2008; Song et al., 2005). Thus, the relationship between RTE cereal consumption and body weight is complex, but it appears that RTE cereal may assist with control of body weight (Crockett \& Affenito, 2012). 
In addition to the potential contribution of RTE cereal consumption to regulation of body weight, findings of the current study point to the favorable association between RTE cereal consumption and nutrient intake. Those persons who consumed RTE cereal most often had improved nutrient intakes and were more likely to meet the dietary reference standard, compared with those who do consume RTE cereal less often or not at all. These results are in agreement with past research conducted in the U.S.(Deshmukh-Taskar et al., 2010; Albertson et al., 2003; Song et al., 2006; Barton et al., 2005; Gibson, 2003; Albertson et al., 2008; Cho et al., 2003), reflecting the significant contribution of RTE cereal to diet quality. However, despite increased nutrient intake in cereal consumers, intake of several nutrients, such as vitamin E, magnesium, and vitamin A, calcium, vitamin D, and potassium, remained below the reference standard. In studies assessing micronutrient intake among Canadians, the prevalence of reduced intake of calcium was found to be undesirably high across all age groups (Poliquin, Joseph, \&Gray-Donald, 2009). Over recent years, calcium fortification and supplement use have reduced the prevalence of inadequacy, yet mean intakes remain below the Dietary Reference Intakes (DRIs), particularly for women over 50 years. Findings of the current study also parallel data from a rigorous study employing dietary assessment interviews of indigenous adults of 44 representative communities of Yukon First Nations ( $\mathrm{n}=797)$, Dene/Métis, $(\mathrm{n}=1007)$ and Inuit $(\mathrm{n}=1525)$. Using the EAR cut-point method, nutrients of concern, which were defined to fall significantly below the goal value included magnesium, folate, vitamin $\mathrm{A}$, vitamin $\mathrm{C}$ and vitamin E. In addition, for those nutrients in which Adequate Intake (AI) reference standards are available, under desirably high nutrient intakes were documented forfiber, n- 6 fatty acids and calcium(Kuhnlein, Receveur, Soueida, \& Berti, 2008). Further, intake of vitamin A was found to be suboptimal, particularly among the younger generations of Inuit men and women (Egeland et al., 2004). These results may reflect a reduced intake of fresh fruits and vegetables and dairy products (Garriguet, 2009) as well as increased consumption of convenience foods, snack foods, and meals eaten away from home (Woodruff \& Hanning, 2009). Thus, nutrition education efforts are necessary to target these shortfall nutrients and to encourage healthful eating patterns at and away from the home environment.

Limitations of the current study should be kept in mind when interpreting these data. Dietary data were collected by self-report, a method that is subject to recall errors and underreporting (Garriguet, 2008). However, instructions provided for panellists to fully describe food intakes and return of daily food intake diaries may offset this limitation. A second limitation is related to the estimates of portion size, which were applied based on the average serving size for age 20 and gender groups reported in national surveys. When estimating the portion size, the estimates assumed that the average serving size applies to all individuals of same age and gender. This assumption clearly provides errors of the estimate for the individual. However, when applied to the total sample it would be expected that mean intakes would approximate estimates of intake provided by dietary survey data (Albertson et al., 2003). This appears to be true because of the agreement with previously published population-based surveys (Cho et al., 2003; Albertson et al., 2003). In addition, it should be noted that differences in the mean comparisons across categories of RTE cereal consumption cannot be explained by an error in accuracy of the estimate of total intake, an error which would be present across all categories (Albertson et al., 2003). Finally, nutrient intake was assessed by using data adjusted for day-to-day variation, which may have reduced error when estimating the prevalence of intakes below a specified reference value (Jahns, Arab, Carriquiry, \& Popkin, 2005).

\section{Conclusions}

Canadians who frequently consume RTE cereals have healthier BMI and are less likely to be overweight or obese compared to those who seldom or never consume RTE cereals. In addition, RTE cereal consumption was related to improved nutrient intakes in Canadians age 12 years and older. As part of a healthful eating pattern, RTE cereal consumption should be encouraged to promote the maintenance of healthy body weight and positive nutrient intake.

\section{Acknowledgment}

Authors acknowledge Arohi Bapna for helping in editing the manuscript.

\section{References}

Albertson, A. M., Affenito, S. G., Bauserman, R., Holschuh, N. M., Eldridge, A. L., \& Barton, B. A. (2009). The relationship of ready-to-eat cereal consumption to nutrient intake, blood lipids, and body mass index of children as they age through adolescence. Journal of American Dietetic Association, 109, 1557-1565. http://dx.doi.org/10.1016/j.jada.2009.06.363

Albertson, A. M., Anderson, G. H., Crockett, S. J., \& Goebel, M. T. (2003). Ready-to-eat cereal consumption: its relationship with BMI and nutrient intake of children aged 4 to 12 years. Journal of American Dietetic Association, 103, 1613-1619. http://dx.doi.org/10.1016/j.jada.2003.09.020 
Albertson, A. M., Thompson, D., Franko, D. L., Kleinman, R. E., Barton, B. A., \& Crockett, S. J. (2008). Consumption of breakfast cereal is associated with positive health outcomes: evidence from the National Heart, Lung, and Blood Institute Growth and Health Study. Nutrition Research, 744-752. http://dx.doi.org/10.1016/j.nutres.2008.09.002

Alexander, K. E., Ventura, E. E., Spruijt-Metz, D., Weigensberg, M. J., Goran, M. I., \& Davis, J. N. (2009). Association of breakfast skipping with visceral fat and insulin indices in overweight Latino youth. Obesity, 17(8), 1528-1533. http://dx.doi.org/10.1038/oby.2009.127

Barton, B. A., Eldridge, A. L., Thompson, D., Affenito, S. G., Striegel-Moore, R. H., Franko, D. L., ... Crockett, S. J. (2005). The relationship of breakfast and cereal consumption to nutrient intake and body mass index: the National Heart, Lung, and Blood Institute Growth and Health Study. Journal of American Dietetic Association, 105, 1383-1389. http://dx.doi.org/10.1016/j.jada.2005.06.003

Berkey, C. S., Rockett, H. R. H., Gillman, M. W., Field, A. E., \& Colditz, G. A. (2003). Longitudinal study of skipping breakfast and weight change in adolescents. International Journal of Obesity, 1258-1266. http://dx.doi.org/10.1038/sj.ijo.0802402

Bowman, S. A., \& Vinyard, B. T. (2004). Fast food consumption of U.S. adults: impact on energy and nutrient intakes and overweight status. Journal of American College of Nutrition, 23, 163-168. Retrieved from http://www.jacn.org/content/23/2/163.long

Bray, G. A., \& Champagne, C. M. (2005). Beyond energy balance: there is more to obesity than kilocalories. Journal of American Dietetic Association, 105(Suppl 1), S17-S23. http://dx.doi.org/10.1016/j.jada.2005.02.018

Burgess-Champoux, T. L., Larson, N. I., Neumark-Sztainer, D. R., Hannan, P. J., \& Story, M. T. (2010). Longitudinal and secular trends in adolescent whole-grain consumption, 1999-2004. American Journal of Clinical Nutrition, 91, 154-159. http://dx.doi.org/10.3945/ajen.2009.28250

Centers for Disease Control and Prevention (CDC). National Center for Health Statistics (NCHS). (2004). National Health and Nutrition Examination Survey Data. Hyattsville, MD: U.S. Department of Health and Human Services, Centers for Disease Control and Prevention (1999-2004). Retrieved from http://www.cdc.gov/nchs/nhanes.htm

Cho, S., Dietrich, M., Brown, C. J., Clark, C. A., \& Block, G. (2003). The effect of breakfast type on total daily energy intake and body mass index: results from the Third National Health and Nutrition Examination Survey (NHANES III). Journal of American College of Nutrition, 22, 296-302. Retrieved from http://www.jacn.org/content/22/4/296.long

Crockett, S. J., \& Affenito, S. J. (2012). Cereals, Breakfast. In M. Ripple (Ed.), Encyclopedia of Lifestyle Medicine and Health (pp. 530-37). Sage Publication.

Deshmukh-Taskar, P. R., Nicklas, T. A., O’Neil, C. E., Keast D. R., Radcliffe, J. D., \& Cho, S. (2010). The relationship of breakfast skipping and type of breakfast consumption with nutrient intake and weight status in children and adolescents: The National Health and Nutrition Examination Survey 1999-2006. Journal of American Dietetic Association, 110(6), 869-878. http://dx.doi.org/10.1016/j.jada.2010.03.023

Egeland, G., M., Berti, P., Soueida, R., Arbour, L. T., Receveur, O., \& Kuhnlein, H. (2004). Age differences in vitamin A intake among Canadian Inuit. Canadian Journal of Public Health, 95(6), 465-469. Retrieved from http://journal.cpha.ca/index.php/cjph/article/view/548/548

Garriguet, D. (2008). Under-reporting of energy intake in the Canadian Community Health Survey. Health Rep, 19(4), 37-45. Retrieved from http://www.statcan.gc.ca/pub/82-003-x/2008004/article/10703-eng.htm

Garriguet, D. (2009). Diet quality in Canada. Health Rep, 20(3), 41-52. Retrieved from http://www5.statcan.gc.ca/bsolc/olc-cel/olc-cel?lang=eng\&catno=82-003-X200900310914

Gibson, S. (2003). Micronutrient intakes, micronutrient status and lipid profiles among young people consuming different amounts of breakfast cereals: further analysis of data from the National Diet and Nutrition Survey of Young People aged 4 to 18 years. Public Health Nutrition, 6, 815-820. http://dx.doi.org/10.1079/PHN2003493

Health Canada, Canadian Nutrient File. (2007b). Version. Retrieved from http://www.hc-sc.gc.ca/fn-an/nutrition/fiche-nutri-data/index-eng.php 
Howarth, N. C., Huang, T. T., Roberts, S. B., Lin, B. H., \& McCrory, M. A. (2007). Eating patterns and dietary composition in relation to BMI in younger and older adults. International Journal of Obesity, 31, 675-684. http://dx.doi.org/10.1038/sj.ijo.0803456

Jahns, L., Arab, L., Carriquiry, A., \& Popkin, B. M. (2005). The use of external within-person variance estimates to adjust nutrient intake distributions over time and across populations. Public Health Nutrition, 8, 69-76. http://dx.doi.org/10.1079/PHN2004671

Kant, A. K., \& Graubard, B. I. (2006). Secular trends in patterns of self-reported food consumption of adult Americans: NHANES 1971-1975 to NHANES 1999-2002. American Journal of Clinical Nutrition, 1215-1223. Retrieved from http://ajcn.nutrition.org/content/84/5/1215.full

Katzmarzyk, P. T. (2002). The Canadian obesity epidemic, 1985-1998. Canadian Medical Association Journal, 166(8), 1039-40. Retrieved http://www.cmaj.ca/content/166/8/1039.full?sid=58daf749-2973-4ff0-8b9f-77a72741 ea72

Keski-Rahkonen, A., Kaprio, J., Rissanen, A., Virkkunen, M., \& Rose, R. J. (2003). Breakfast skipping and health-compromising behaviors in adolescents and adults. European Journal of Clinical Nutrition, 57, 842-853. http://dx.doi.org/10.1038/sj.ejen.1601618

Kuhnlein, H. V., Receveur, O., Soueida, R., \& Berti, P. R. (2008). Unique patterns of dietary adequacy in three cultures of Canadian Arctic indigenous peoples. Public Health Nutrition, 11(4), 349-360. http://dx.doi.org/10.1017/S1368980007000353

Langlois, K., Garriguet, D., \& Findlay, L. (2009). Diet composition and obesity among Canadian adults. Health Rep., 20(4), 11-20. Retrieved from http://www.statcan.gc.ca/pub/82-003-x/2009004/article/10933-eng.pdf

Ma, Y., Bertone,E. R., Stanek, E. J., Reed, G. W., Hebert, J. R., Cohen, N. L., ... Ockene, I. S. (2003). Association between eating patterns and obesity in a free-living US adult population. American Journal of Epidemiology, 158, 85-92. http://dx.doi.org/10.1093/aje/kwg117

McLaren, L., Godley, J., \& MacNairn, Ian A. S. (2009).Social class, gender, and time use: Implications for the social determinants of body weight. Health Rep., 20(4), 65-73. Retrieved from http://www.statcan.gc.ca/pub/82-003-x/2009004/article/11020-eng.htm

Nicklas, T. A., McQuarrie, A., Fastnaught, C., \& O’Neil, C. E. (2002). Efficiency of breakfast consumption patterns of ninth graders: nutrient-to-cost comparisons. Journal of American Dietetic Association, 102, 226-233. http://dx.doi.org/10.1016/S0002-8223(02)90053-2

Poliquin, S., Joseph, L., \& Gray-Donald, K. (2009). Calcium and vitamin D intakes in an adult Canadian population. Canadian Journal of Dietetics Practice and Research, 70(1), 21-27. Retrieved from http://dcjournal.metapress.com/content/9207634032127357/?p=8ef9f9c9cf924e12ae49bc71b8319b96\&pi= 4

Rampersaud, G. C., Pereira, M. A., Girard, B. L., Adams, J., \& Metzl, J. D. (2005). Breakfast habits, nutritional status, body weight, and academic performance in children and adolescents. Journal of American Dietetic Association, 105(5), 743-760. http://dx.doi.org/10.1016/j.jada.2005.02.007

Slater, J., Green, C. G., Sevenhuysen, G., Edginton, B., O’Neil, J., \& Heasman, M. (2009). The growing Canadian energy gap: more the can than the couch? Public Health Nutrition, 12(11), 2216-2224. http://dx.doi.org/10.1017/S1368980009990309

Song, W. O., Chun, O. K., Kerver, J., Cho, S., Chung, C. E., \& Chung, S. J. (2006). Ready-to-eat breakfast cereal consumption enhances milk and calcium intake in the US population. Journal of American Dietetic Association, 106, 1783-1789. http://dx.doi.org/10.1016/j.jada.2006.08.015

Song, W. O., Chun, O. K., Obayashi, S., Cho, S., \& Chung, C. E. (2005). Is consumption of breakfast associated with body mass index in US adults? Journal of American Dietetic Association, 105, 1373-1382. http://dx.doi.org/10.1016/j.jada.2005.06.002

Steffen, L. M., Jacobs Jr., D. R., Murtaugh, M. A., Moran, A., Steinberger, J., Hong, C. P., \& Sinaiko, A. R. (2003). Whole grain intake is associated with lower body mass and greater insulin sensitivity among adolescents. American Journal of Epidemiology, 158, 242-250. http://dx.doi.org/10.1093/aje/kwg146

The NPD Group. (2008) National Eating Trends 2007-2008. Rosemount, IL. Retrieved from https://www.npdgroup.ca/wps/portal/npd/ca/home/?utm_source=npdUS\&utm_medium=TopLink\&utm_ca mpaign=USCanadaLink 
Vanasse, A., Demers, M., Hemiari, A., \& Courteau, J. (2006). Obesity in Canada: where and how many? International Journal of Obesity, 30, 677-683. http://dx.doi.org/10.1038/sj.ijo.0803168

Williams, B. M., O’Neil, C. E., Keast, D. R., Cho, S., \& Nicklas, T. A. (2009). Are breakfast consumption patterns associated with weight status and nutrient adequacy in African-American children? Public Health Nutrition, 12, 489-496. http://dx.doi.org/10.1017/S1368980008002760

Williams, P., Grafenauer, S., \& O’Shea, J. (2008). Cereal grains, legumes, and weight management: a comprehensive review of the scientific evidence. Nutrition Reviews, 66, 171-182. http://dx.doi.org/10.1111/j.1753-4887.2008.00022.x

Woodruff, S. J., \& Hanning, R. M. (2009). Effect of meal environment on diet quality rating. Canadian Journal of Dietetics Practice and Research, 70(3), 118-124. Retrieved from http://dcjournal.metapress.com/content/np1400141t404h0m/ 